\title{
Investigación arqueológica, sector Qolqas del parque arqueológico de Raqchi, Canchis-Cusco
}

\author{
Archaeological research, Qolqas sector of the Raqchi \\ archaeological park, Canchis-Cusco
}

\author{
Marisa G. Quispe Cuno \\ https://orcid.org/oooo-0003-2211-0991 \\ Dirección Desconcentrada de Cultura Cusco \\ maquicu12@hotmail.com
}

\section{RESUMEN}

El presente artículo es el resultado preliminar del año uno, de ejecución con referencia al expediente técnico integral aprobado de las trece unidades de excavación del sector Qolqas del Parque Arqueológico de Raqchi del Distrito de San Pedro, Provincia de Canchis, Departamento Cusco. Las cuales se enfocan en el asociado del material cultural evidenciado y la conservación y puesta en valor del sector Qolqas. Se tiene como objetivo planteado analizar la función de los recintos circulares denominados Qolqas y establecer la secuencia ocupacional del sector, dichos objetivos serán desarrollados a través de la investigación arqueológica en el proceso de la investigación arqueológica.

Palabras clave: Sector Qolqas; estructura circular; material cultural.

\section{ABSTRACT}

This article is the preliminary result of year one, of execution with reference to the approved technical file, of the thirteen excavation units of the Qolqas sector of the Archaeological Park of Raqchi of the District of San Pedro, Province of Canchis, Cusco Department. Which focus on the associate of the cultural material eviden- 
ced and the conservation and valorization of the Qolqas sector. Its objective is to analyze the function of circular enclosures called Qolqas and establish the occupational sequence of the sector, these objectives will be developed through archaeological research in the process of archaeological research.

Keywords: Qolqas Sector; circular structure; cultural material.

RECiBiDO: 23/09/2019 - ACEPTADO: 15/09/2020 - PubLicADO: 10/05/2021

\section{INTRODUCCIÓN}

El Proyecto de Investigación Arqueológica con fines de conservación y puesta en valor "Recuperación del Monumento Prehispánico Sector Qolqas, del Parque Arqueológico de Raqchi, Distrito de San Pedro, Provincia de Canchis, departamento Cusco, inició con los trabajos del proyecto en octubre del 2017 correspondiente al año uno a través de la Dirección Desconcentrada de Cultura Cusco del Ministerio de Cultura, en el marco de invierte. pe. Y en cumplimiento al Reglamento de Investigaciones Arqueológicas aprobado mediante D.S. $\mathrm{N}^{\circ}$ 003-2014-MC. De fecha de 04 de octubre 2014 y las normas legales sobre el patrimonio cultural de la Nación. Ley № 28296 dichas leyes especifican las labores de defensa, protección, promoción, propiedad y régimen legal de los bienes que constituye el Patrimonio Cultural de la Nación. El proyecto de investigación arqueológica con fines de conservación y puesta en valor, tiene como objetivo alcanzar mediante un plan de difusión los resultados del año 1 de la investigación arqueológica. El propósito de la investigación arqueológica radica en analizar la función de los recintos denominados Qolqas y establecer la secuencia ocupacional del sector en relación al Parque Arqueológico de Raqchi a través de la evidencia arqueológica, como: la cerámica, metales, líticos, óseo y los elementos funcionales de la distribución arquitectónica propia mente dicha (figura 1).

\section{ANTECEDENTES Y TRABAJOS PREVIOS EN EL SECTOR QOLQAS DEL PAR- QUE ARQUEOLÓGICO DE RAQCHI}

Después de las descripciones de los cronistas (Betanzos 1551/1987; Cieza de León 1553/1984 y 1985; Inca Garcilaso de la Vega 1609/1985; entre otros), no se tenía noticia del actual Parque Arqueológico de Raqchi, hasta la llegada de E. George Squier (1863-1865/1974). Las investigaciones han tomado como punto de inicio y referencia las descripciones de Squier. Sin embargo, se ha investigado algunas fuentes bibliográficas que provienen de la década de 1760 . Se trata de las «Descripciones geográficas del Perú» (1764-1768), elaborado por el cosmógrafo mayor del reino, Cosme Bueno, donde se señala que, en las inmediaciones del distrito de San Pedro de Cacha, concretamente en el paraje de Rache (Raqchi), se encuentra un edificio antiguo y grande labrado de piedra y adobe construido sobre un conjunto de andenes, que en tiempos inmemoriales fue «Templo de Viracocha» (Cfr. Guerra, 1982, p. 15). Según otra des- 


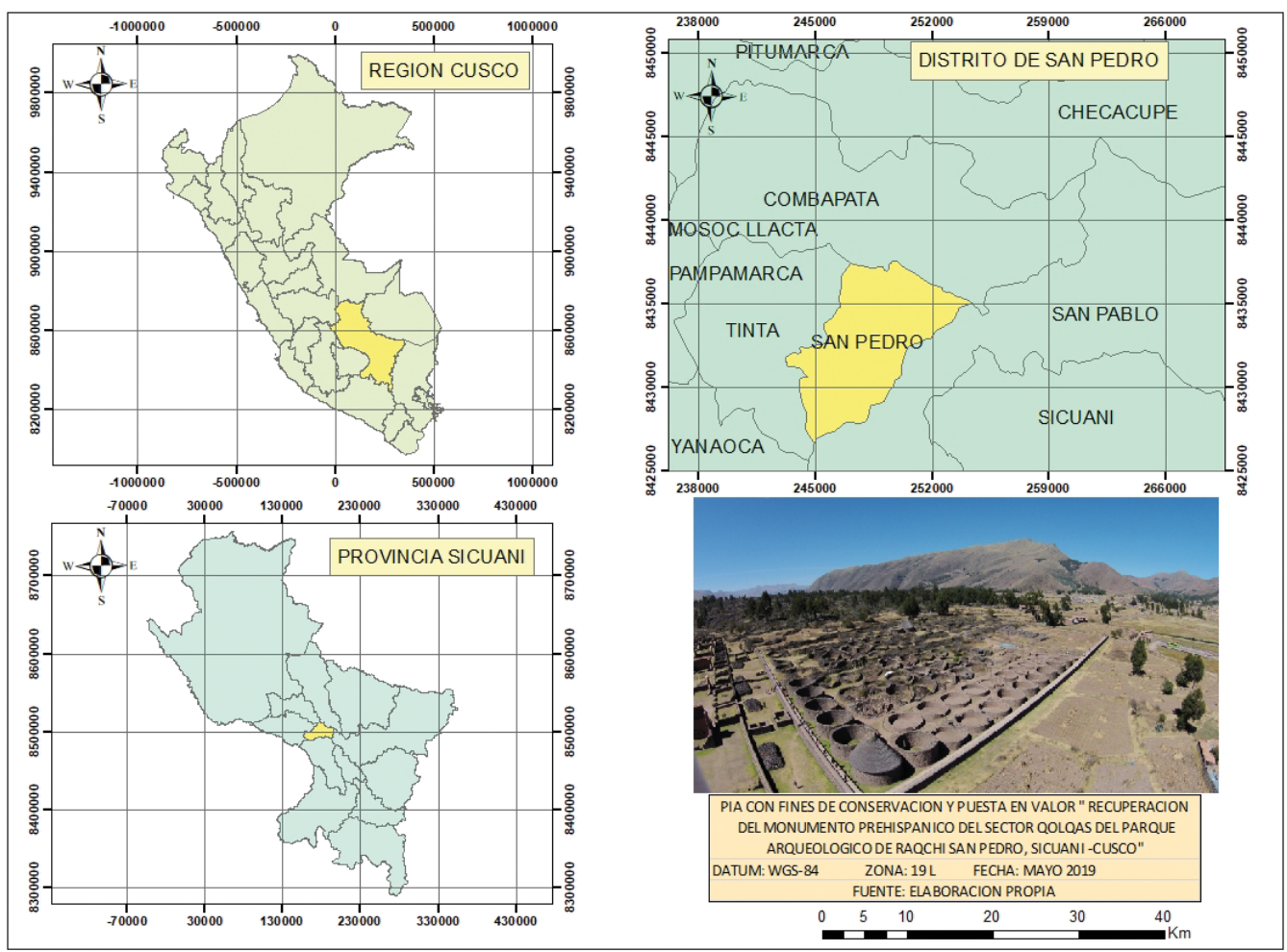

Figura. 01. Mapa de ubicación del sector Qolqas del Parque Arqueológico de Raqchi

cripción de la época: «Descripción corográfica de la provincia de Canas y Canchis» (1790-1795), escrito por Sofronio (seudónimo de José Mariano Millán de Aguirre), señala que dentro del territorio de las tribus $\mathrm{K}^{\prime}$ anas y Canchis, inmediato al pueblo de San Pedro de Cacha, específicamente en el centro de Riacche (Raqchi), se ven las ruinas de un suntuoso templo dedicado al ídolo Viracocha, además de otros fragmentos de buenos edificios que dan a entender fueron residencia de gentes acomodadas y distinguidas (El Mercurio Peruano: 1790 - 1795. Volumen II. Antología).

Desde entonces pasarían muchos años hasta la venida de George Squier (18631865), quien arribó al pueblo de Cacha y en sus cercanías vio el «Templo de Viracocha». Luego de recorrer, observó, dibujó y describió el estado de conservación en que se hallaba. Posteriormente, en 1937, Luis A. Pardo y Víctor Guillén, realizaron las primeras exploraciones arqueológicas. En 1963, Manuel Chávez Ballón, realizó prospecciones arqueológicas hallando valiosos testimonios correspondientes al periodo formativo. En 1970, el INC-Cusco se hizo cargo del Parque Arqueológico iniciando investigaciones arqueológicas. En 1977, el INC en convenio con la UNESCO a través del Proyecto PER 39 realizaron trabajos de excavación, restauración, evaluación sísmica y descripción de los diferentes sectores, incluido las Qolqas. En 


\begin{tabular}{|c|c|c|c|}
\hline UE & \begin{tabular}{|c|} 
RECINTO/ESPACIO \\
ABIERTO
\end{tabular} & MATERIAL CULTURAL & $\begin{array}{c}\text { CONTEXTO ARQUEOLÓGICO } \\
\text { Y/O CARACTERÍSTICAS }\end{array}$ \\
\hline 01 & $\begin{array}{l}\text { R: A- } 06 \text { y A- } 07 \\
\text { Espacio perimetral y pasadizo } \\
\text { longitudinal } 01\end{array}$ & $\begin{array}{l}\text { Dos agujas metálicas. } \\
\text { Botella Wari estilo Chakipampa. } \\
\text { Fragmentos de cerámica de Horizonte Tardío } \\
\text { (Inka sin decoración) }\end{array}$ & $\begin{array}{l}\text { Fosa de huaqueo } \\
\text { Restos óseos de camélido } \\
\text { Piso de ocupación Inka } \\
\text { Ducto de evacuación de aguas pluviales }\end{array}$ \\
\hline 02 & $\begin{array}{l}\text { R: B-06 } \\
\text { Pasadizo longitudinal } 02 \text { y } 03\end{array}$ & $\begin{array}{l}\text { Dos agujas metálicas } \\
\text { Fragmentos de cerámica del Horizonte } \\
\text { Tardío (Inka sin decoración) } \\
\text { Dos cuentas de crisocola }\end{array}$ & $\begin{array}{l}\text { Tratamiento de piso Inka (empedrado) } \\
\text { Ceniza y carbón disperso }\end{array}$ \\
\hline 03 & $\begin{array}{l}\text { R: C-06 y E-06 } \\
\text { Pasadizo longitudinal } 02 \text { y } 03\end{array}$ & 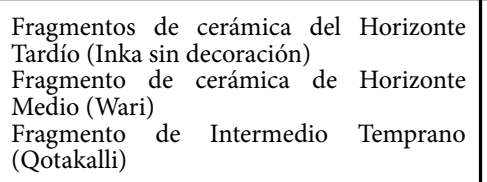 & $\begin{array}{l}\text { Piso de ocupación Inka } \\
\text { Restos óseos de camélido } \\
\text { Carbón vegetal }\end{array}$ \\
\hline 04 & $\begin{array}{l}\text { R: C- } 08 \text { y C- } 09 \\
\text { Pasadizo longitudinal } 02 \text { y } 03\end{array}$ & $\begin{array}{l}\text { Punta lítica peciolada } \\
\text { Fragmento lítico de tunawa } \\
\text { Percutores líticos }\end{array}$ & $\begin{array}{l}\text { Piso de ocupación Inka } \\
\text { Tratamiento de piso Inka (empedrado) } \\
\text { Carbón de Solanum tuberosum (papa } \\
\text { deshidratada) } \\
\text { Restos de fogón }\end{array}$ \\
\hline 05 & $\begin{array}{l}\text { R: C-10 } \\
\text { Pasadizo longitudinal } 02 \text { y } \\
03\end{array}$ & $\begin{array}{l}\text { Tupu fragmentado } \\
\text { Dos agujas metálicas } \\
\text { Fragmentos de cerámica del Horizonte } \\
\text { Tardío (Inka sin decoración) }\end{array}$ & $\begin{array}{l}\text { Piso de ocupación Inka } \\
\text { Restos óseos de camélido } \\
\text { Ceniza dispersada } \\
\text { Tapiado de vano de acceso }\end{array}$ \\
\hline 06 & Pasadizo longitudinal 01 & $\begin{array}{l}\text { Fragmentos de cerámica de Horizonte Tardío } \\
\text { (Inka sin decoración) }\end{array}$ & $\begin{array}{l}\text { Piso de ocupación Inka } \\
\text { Restos óseos de camélido }\end{array}$ \\
\hline 07 & $\begin{array}{l}\text { R: A-07, A-08 y B-08 } \\
\text { Pasadizo longitudinal } 01\end{array}$ & $\begin{array}{l}\text { Fragmentos de cerámica de Horizonte } \\
\text { Tardío (Inka sin decoración) }\end{array}$ & Piso de ocupación Inka \\
\hline 08 & Pasadizo longitudinal 01 & $\begin{array}{l}\text { Fragmentos de cerámica del Horizonte } \\
\text { temprano (Chanapata) }\end{array}$ & Piso de ocupación Inka \\
\hline 09 & Pasadizo longitudinal 02 & $\begin{array}{l}\text { Fragmentos de cerámica del Horizonte } \\
\text { Tardío y Horizonte Temprano. } \\
\text { Fusayola de cerámica }\end{array}$ & Piso de ocupación Inka \\
\hline 10 & $\begin{array}{l}\text { R: E-05 y F-06 } \\
\text { Pasadizo longitudinal } 03,04 \\
\text { y } 05\end{array}$ & $\begin{array}{l}\text { Jarra del Horizonte Tardío (Inka sin } \\
\text { decoración) } \\
\text { Una aguja metálica } \\
\text { Molusco fosilizado } \\
\text { Fragmentos de cerámica del Horizonte } \\
\text { Tardío (Inka sin decoración) }\end{array}$ & $\begin{array}{l}\text { Piso de ocupación Inka empedrado } \\
\text { Tratamiento de drenaje de aguas } \\
\text { pluviales } \\
\text { Grano de almidón de maíz (Zea mays) } \\
\text { Osamenta calcinada de animal } \\
\text { Chenopodium quinoa (quinua) } \\
\text { Ipomoea batatas (camote) }\end{array}$ \\
\hline 11 & $\begin{array}{l}\text { R: F-09, F-10 y F-11 } \\
\text { Pasadizo longitudinal } 04 \text { y } 05\end{array}$ & $\begin{array}{l}\text { Dos alisadores de cerámica } \\
\text { Una fusayola de cerámica } \\
\text { Una punta de obsidiana } \\
\text { Un percutor lítico } \\
\text { Dos secciones de pinza } \\
\text { Una escoria metálica }\end{array}$ & $\begin{array}{l}\text { Piso de ocupación Inka } \\
\text { Entierro de un cánido individuo } \\
\text { adulto de familia Canidae (F-10) }\end{array}$ \\
\hline 12 & R: A-09 a A-12 & $\begin{array}{l}\text { Fragmentos de cerámica del Horizonte } \\
\text { Tardío (Inka sin decoración) } \\
\text { Dos tupus metálicos }\end{array}$ & $\begin{array}{l}\text { Piso de ocupación Inka } \\
\text { Tratamiento de piso Inka (A-10) } \\
\text { Contexto funerario secundario de un } \\
\text { individuo adulto (A-12) }\end{array}$ \\
\hline 13 & $\begin{array}{l}\text { R: A-02 a A-06 } \\
\text { Pasadizo longitudinal } 01\end{array}$ & $\begin{array}{l}\text { Urpu del Periodo Intermedio } \\
\text { (¿Local?) } \\
\text { Una aguja metálica } \\
\text { Una tunawa lítica } \\
\text { Una punta de proyectil }\end{array}$ & $\begin{array}{l}\text { Piso de ocupación Inka } \\
\text { Almidón de maíz (Zea mays) }\end{array}$ \\
\hline
\end{tabular}


esta misma fecha, Gasparini y Margolies (1977), siguiendo los relatos de Garcilaso visitó el «Templo de Wiracocha» al que comparó con una gran Kallanka Inka, y admitieron que las construcciones circulares son depósitos o Qolqas. Años más tarde el INC-Cusco en convenio con la Misión Arqueológica Española, dirigida por Manuel Ballesteros (desde 1978 hasta 1983), realizaron diversos trabajos de investigación, mantenimiento y conservación. De otro lado, entre 1980 y 1982, Juana Maysundo, realizó excavaciones arqueológicas encontrando evidencias desde el formativo (Qaluyu-Marcavalle). De otro lado, Oscar Núñez del Prado, en 1981, efectuó trabajos de excavación y prospección en los sectores del «Templo de Wiracocha», «Puqllanapampa» y «Kalli Kalli» (sector de las Qolqas); con respecto a este último sector propuso que son los restos del antiguo poblado de Kacha.

En los años 1990 y 2000, se han ejecutado trabajos de investigación arqueológica, por parte del INC-Cusco como por investigadores extranjeros (Bill Sillar y Emily Dean). El INC realizó trabajos de limpieza, mantenimiento, conservación, puesta en valor del monumento e investigación arqueológica (Pedro Tacca, Claudio Cumpa, Wilfredo Yepez, Lizbeth Rodríguez, entre otros). En los últimos años se han realizado tesis universitarias (en su mayoría por los estudiantes de Arqueología y Antropología e Historia de la Universidad Nacional de San Antonio Abad), a la fecha se viene ejecutando el proyecto de investigación arqueológica con fines de conservación y puesta en valor por la Dirección Desconcentrada de Cultura Cusco del Ministerio de Cultura.

En el proceso de la investigación está desarrollado desde el enfoque post procesual "La arqueología de la arquitectura debe gestionar, estudiar y conservar una parte de la Cultura Material de las sociedades pasadas" (Mañana Borazas \& Blanco Rotea , 2002, p. 21). Los patrones utilizados en los diseños de asentamiento Inka son los ortogonales y radiales en el caso del sector Qolqas corresponde a una distribución ortogonal.

El plan ortogonal Inka se caracteriza por tener calles que se cruzan perpendicularmente o casi perpendicularmente. Las calles pueden ser exactamente paralelas, pero en general no lo son. No tienen que estar separadas por distancias iguales, los patrones ortogonales Inka se adaptaron a variaciones topográficas, pero en general se encuentran en terrenos planos o inclinados, donde no son necesarios grandes ajustes (Hyslop, 2016, p. 244).

La estructura arquitectónica estudiado en el sector Qolqas se caracteriza por una distribución espacial asentado de planta circular, con edificios asociados a espacios abiertos o pasadizos longitudinales, con patrón claro de organización lineal distribuidas en diez columnas. El sistema de circulación se compone de nueve pasadizos longitudinales paralelos y bien definidos.

En la presente investigación arqueológica del sector intervenido de acuerdo a los resultados de la investigación arqueológica evidenciada corresponde a estructuras circulares del Horizonte Tardío (Inka). Para el año 1, se ha planteado las siguientes 
interrogantes ¿Cuál es la función de los recintos denominados Qolqas?, ¿Cuál es la secuencia ocupacional del sector Qolqas?, dicha problemática se desarrolló en el transcurso de la investigación cuyo objetivo es determinar la función real de las estructuras circulares denominados Qolqas y establecer la secuencia ocupacional en el sector Qolqas.

Métodos y Materiales: El tipo de investigación asumido es básica de alcance explicativo y diseño transversal. La excavación arqueológica se realizó con la técnica de Matriz de Harris, y registro arqueológico. En gabinete se procesó la información, con el uso de software Auto Cad, Microsoft Excel, Harris Matriz Composer, Agisoft Photo Scan.

Resultados: La ejecución del proyecto de investigación arqueológica para el año1, se inició el 04 de octubre del 2017 a octubre del 2018, durante los trabajos se realizó una investigación sistemática en el área de intervención. El sector Qolqas se ubica aproximadamente a 3,495 m s. n. m. El área de intervención tiene un área $24855,48 \mathrm{~m}^{2}$ con área de reserva de $4,124.06 \mathrm{~m}^{2}$; para el año 1 se ha investigado un área de $804,90 \mathrm{~m}^{2}$. Compuesto de trece unidades de excavación (figura ${ }^{\circ}$ 02), el material cultural obtenido durante las excavaciones arqueológicas es de fragmentos de cerámicas, metales, elementos líticos, óseos, restos de fogón, carbón vegetal y ceniza disperso, el material cultural evidenciado durante la investigación confirma la ocupación durante el Horizonte Tardío (Inka), que permitió la identificación de muros soterrados, vanos de acceso, tratamientos de piso, drenajes de filtración de aguas pluviales hacia el subsuelo, las estructuras arquitectónicas se caracterizan por recintos circulares de mampostería ordinaria, con un vano de acceso de $0.60 \mathrm{~m}$ en el umbral con un diámetro que oscila entre 8.50 a $9.50 \mathrm{~m}$ de diámetro exterior.

\section{MATERIAL CULTURAL DEL SECTOR QOLQAS DEL PARQUE ARQUEOLÓGICO DE RAQCHI DEL AÑO 1}

Se tiene material cultural diagnóstico en total de 15, de los cuales 13 son de metal (08 agujas, 03 tupus y 02 pinzas), y 02 de cerámica que corresponden a 01 botella Wari de estilo Chakipampa y 01 jarra de Horizonte Tardío (Inka) (ver figura 03).

\section{MATERIAL CULTURAL METÁLICO}

Los tupus o prendedores son objetos que se utilizaban para prender o sujetar la manta o lliclla que llevaba la mujer sobre sus hombros. También se usaban en pares para sujetar el anaku o vestido a la altura de los hombros (Vetter Parodi \& Filomena Guerra, 2017, p. 174).

Según los resultados de análisis químico por fluorescencia de rayos X (Gamarra Gamio, 2018).Tupu de bronce (Cu: 69,17\% y Sn: 8,11\%) compuesto de cabeza laminada de forma semiesférica u ovalada (con evidencia de faltantes de borde), en la zona inferior y central de la cabeza se observa una perforación circular, presenta bastago 


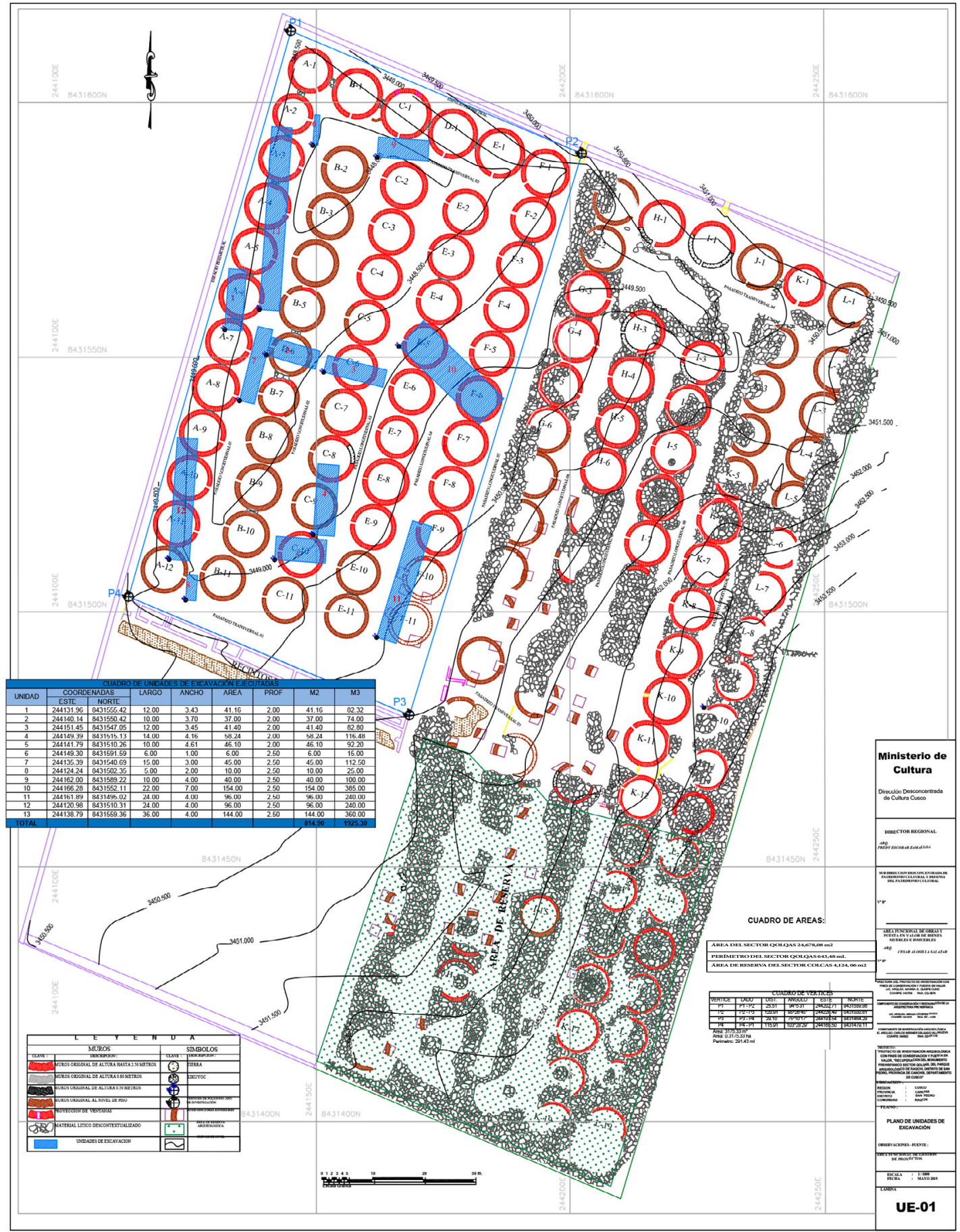

Figura 02. Plano del sector Qolqas del Parque Arqueológico de Raqchi, con las 13 UE del año 1. 




Figura 03. Frecuencia de material cultural del año 1

\section{CERÁMICA DEL HORIZONTE TARDÍO (1400 D.C- 1532 D.C)}

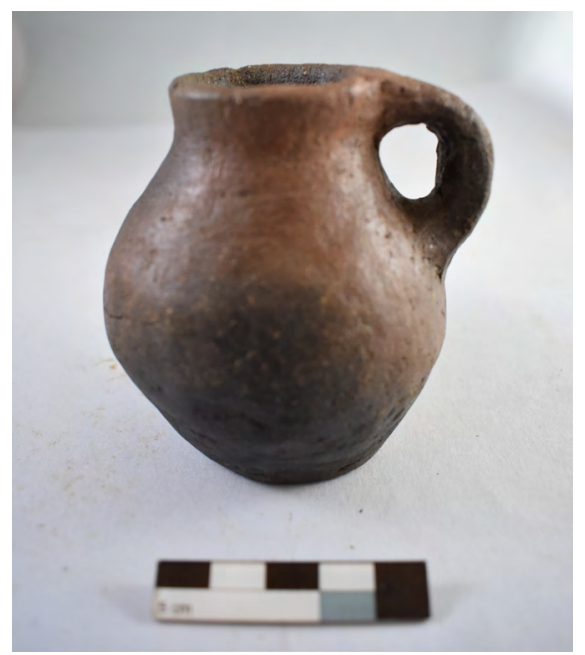

Figura 04. Jarra de base plana, con presencia parcial de hollín en la parte inferior externa del cuerpo y sin decoración, vasija de uso doméstico. UE 01, deposito 43 y nivel $-3.95 m$

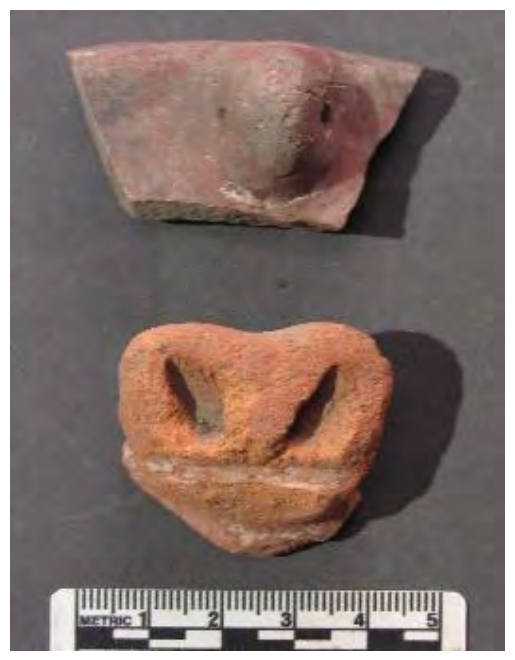

Figura. 05. Aplicaciones plásticas de aribalo, deposito 03 y nivel $-3.48 \mathrm{~m}$ 


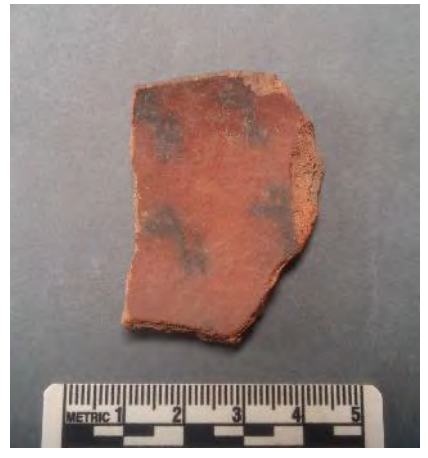

Figura 06. Fragmento de cerámica estilo Inka Pacaje, depósito 03 y nivel $-3.47 m$

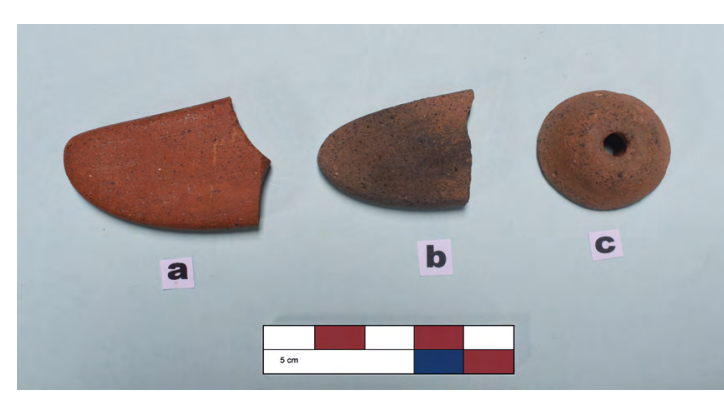

Figura 07. Alisadores elaborados en cerámica para el acabado de objetos

\section{CERÁMICA DEL INTERMEDIO TARDÍO LOCAL. (1000 D.C- 1400 D.C)}
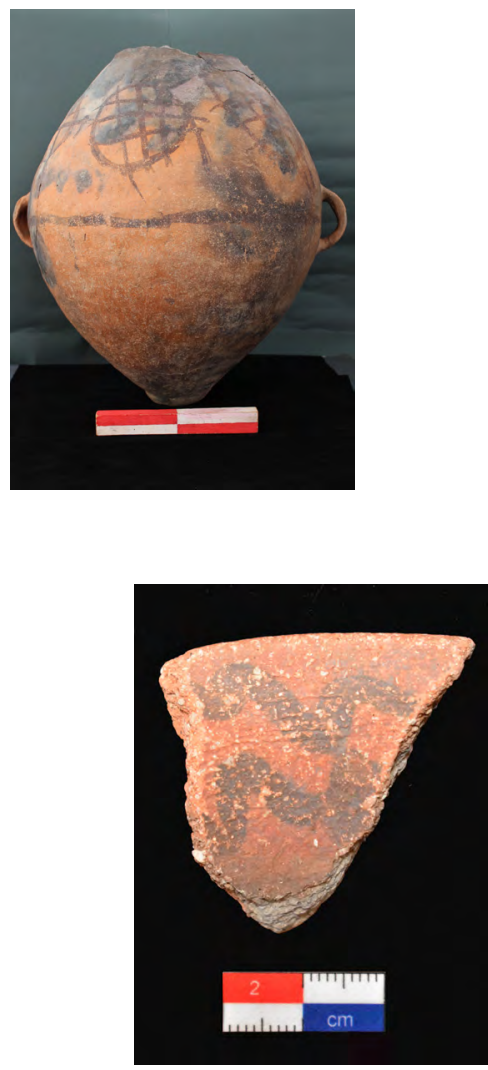

Figura 09. Fragmento de borde redondeado con decoración de líneas onduladas sobre fondo anaranjado, deposito 18 a un nivel de $-3.12 m$
Figura. 08. Urpu de uso doméstico, con carencia de cuello, de cuerpo elipsoide en posición vertical, tiene dos asas laterales cintadas en posición vertical ubicadas en la parte media lateral del cuerpo, presenta una base de forma cónica con terminación aguda de tipo convexa, con decoración de motivos geométricos circulares, líneas gruesas de color negro sobre fondo anaranjado en forma de redes y una línea que va dispuesta en posición horizontal que circunda alrededor del objeto por la parte media del cuerpo, hallado en la UE 13, recinto A-03, deposito 18 y nivel $-3.81 \mathrm{~m}$

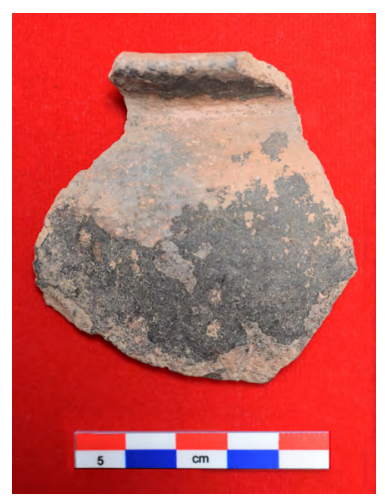

Figura 10. Fragmento sin decoración, con presencia de remanentes de hollín en la superficie exterior, UE.12, deposito 14 an nivel de $-3.75 \mathrm{~m}$ 


\section{CERÁMICA DEL INTERMEDIO TARDÍO LOCAL. (1000 D.C- 1400 D.C)}

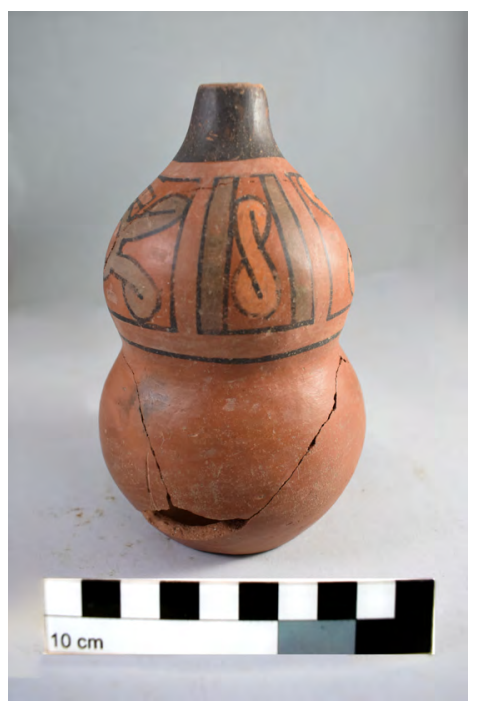

Figura 11. Botella Wari de estilo Chakipampa de labio convexo, borde recto, cuello cónico con pintura negra, cuerpo biglobular y base plana, presenta una inflexión en la parte media del cuerpo, en la parte superior tiene decoración policroma con motivo zoomorfo (pulpo de color gris y anaranjado ), un diseño en forma de " $S$ " (color gris y naranja) en posición vertical sobre fondo anaranjado, ambos motivos se disponen en los extremos opuestos dentro de una figura cónica, el objeto muestra una línea de color negro dispuesto en forma horizontal que rodea al rededor del mismo. El tratamiento de superficie exterior es alisado uniforme con engobe anaranjado. El objeto cultural (cerámica Wari) está consolidado de 09 fragmentos, que hace un $80 \%$ de su integridad. UE 01 , recinto A-07, deposito 43 y nivel $-3.95 m$

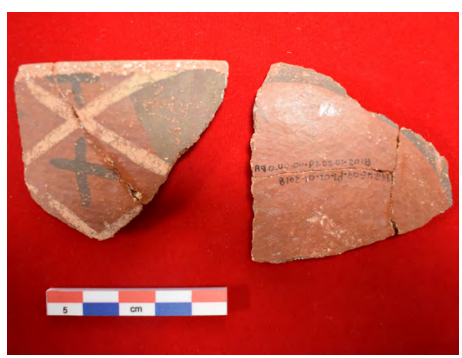

Figura 12. Fragmentos de cerámica con motivos decorativos de líneas en forma de $X^{*}$ concatenadas dispuestas horizontalmente de color crema en cuyo interior presenta líneas cruzadas formando una cruz de color negro sobre fondo anaranjado. UE. 09, pasadizo transversal 02, depósito 01, nivel $-3.47 m$

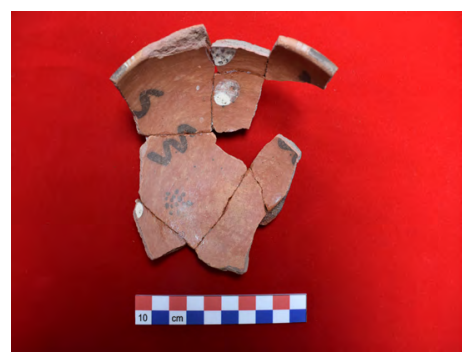

Figura 13. Fragmentos de cerámica con motivos decorativos de líneas ondulantes en cuyo interior presenta puntos con fondo blanco, colocados indistintamente. UE 02 , recinto $B-06$, deposito 07 , nivel-2.75 m

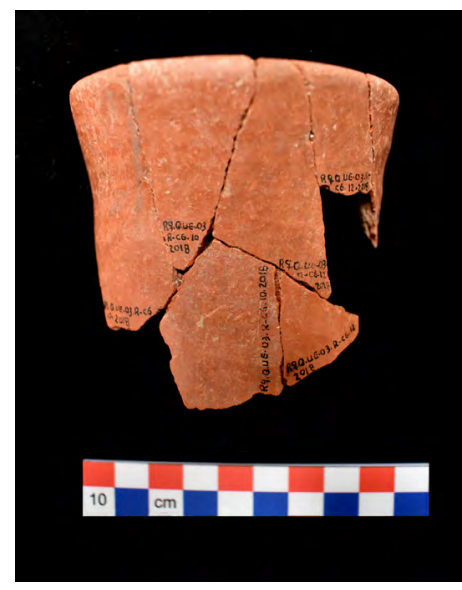

Figura 14. Fragmento de un vaso, con borde redondeado, ligeramente evertido, alisado $y$ pulido fino en la superficie interna y externa. UE 03, deposito 12, nivel $-2.79 \mathrm{~m}$ 
alargado de forma tubular que termina en punta (figura 15).Tupu de bronce (Cu: 82,03\% y Sn: 4,29\% ) compuesto de cabeza laminada en cuya sección anterior del cuerpo de la cabeza presenta una rajadura con desgaste de borde, además la aguja o barra tubular esta doblado y debilitado en la sección media del bastón, con perdida de capas metálicas (figura 15 y 16). Ambos tupus fueron hallados asociado a un contexto funerario secundario de un individuo y un tupu (Cu: 83,39\% y Sn: 1.77\%) con pérdida de cabeza en un 90\% (figura17)

Depilador: El cuidado de la apariencia personal y embellecimiento puede llegar a ser parte del quehacer cotidiano. En las sociedades andinas prehispánicas estas prácticas están representadas por objetos como las pinzas o depiladores. La remoción mecánica de pilosidad facial o de alguna otra zona del cuerpo fue atendida utilizando estos aparatos hechos a partir de láminas de metal recortado y dobladas. Este depilador tiene un cuerpo formado por dos secciones acampanadas en cada extremo y una zona central adelgazada y doblada que sirve de agarradera (Ministerio de Cultura, 2016, p. 50)

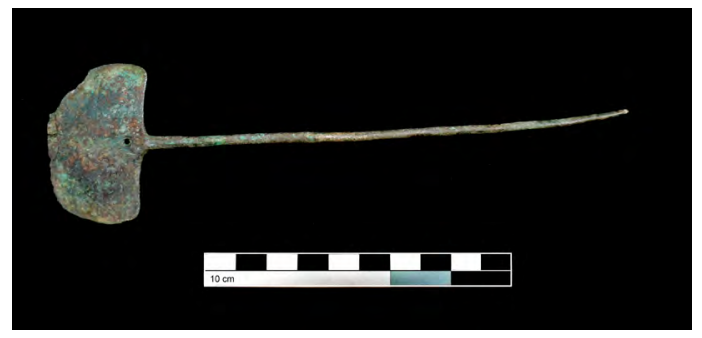

Figura 15. Tupu de Horizonte Tardío; Bronce, vaciado, martillado y perforado: $19.09 x$ $5,4 \times 0,04 \mathrm{~cm}$. UE 12, Recinto A-12, deposito 61, Nivel-3.18m



Figura 16. Tupu de Horizonte Tardío; Bronce, vaciado, martillado y perforado; $19.02 x$ $5.04 \times 0.03 \mathrm{~cm}$. UE 12, Recinto A-12, deposito 61, Nivel-3.25m

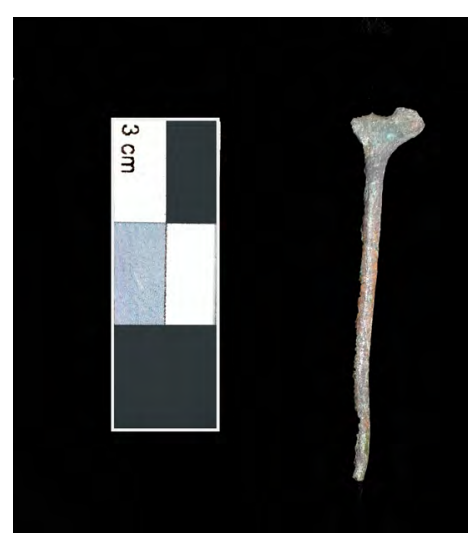

Figura 17. Fragmento de tupu: 3,07x 0,08 $\times 0.02 \mathrm{~cm}$ 
Pinza con faltante de una sección, que presenta un extremo de forma acampana$\mathrm{da}$, una zona central delgada y doblada que sirve de agarradera. Ambas pinzas constituidas de bronce (Cu: 68,36 \% y Sn: 12,43 \%, figura 18) y (Cu: 68,72 \% y Sn: 10.07 \%, figura 19).

Las agujas metálicas constituidas de cobre $(\mathrm{Cu})$, estaño $(\mathrm{Sn})$ y trazas de arsenico (As), siendo las más frecuentes aquellas de forma alargada tubular que presenta orificio con función de ojal en el extremo superior y un extremo inferior puntiagudo (figura 20).

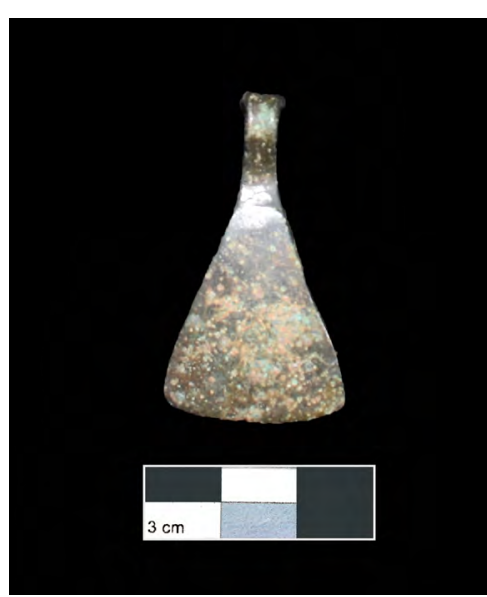

Figura 18. Pinza de Horizonte Tardío, bronce, laminado, embutido y doblado: 3,02 $x$ $1,09 \times 0.2 \mathrm{~cm}$. UE.11, recinto F-10, deposito 38 y Nivel-1.25m.

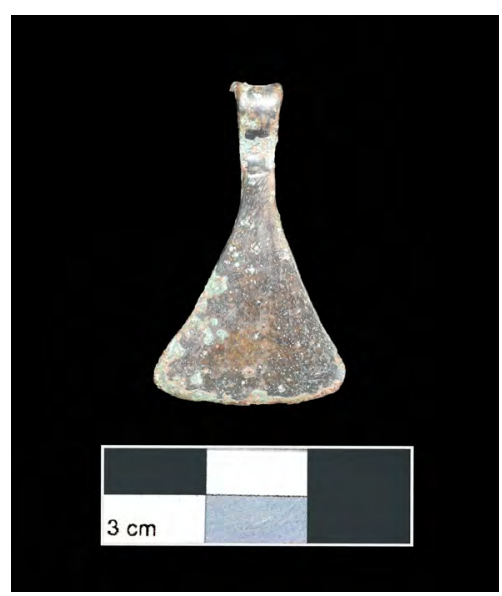

Figura 19. Pinza de Horizonte Tardío; bronce, laminado, embutido y doblado: $4,08 \times 2,09 \times 0,02 \mathrm{~cm}$. UE.11, recinto F-09, deposito 32, Nivel $-1.34 m$

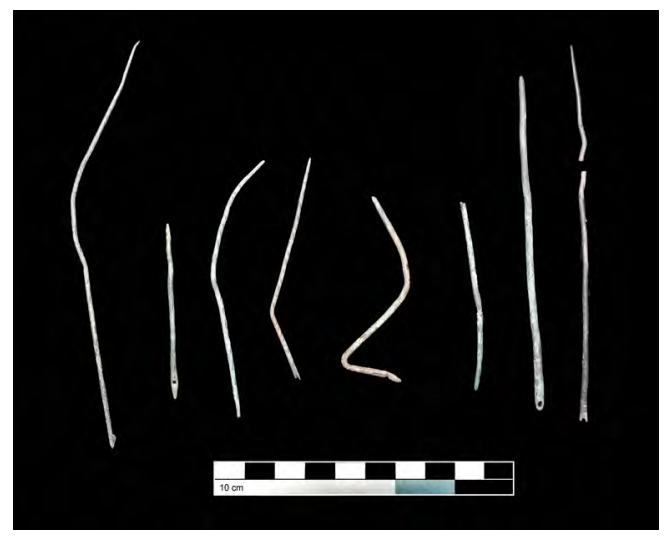

Figura 20. Agujas metálicas de Horizonte Tardío (Inka) 
Material óseo: Se registró un contexto funerario secundario de forma circular de $0.58 \mathrm{~m}$ diámetro y $0.43 \mathrm{~m}$ de profundidad que contenía restos de un individuo hallado en el interior de la unidad y recinto A-12 próximo al muro del lado oeste, "como resultado se ha identificado 03 individuos de los cuales 01 individuo corresponde a un adulto mayor (35-40 años a más) y dos corresponde a individuos subadultos (menores de 20 años)" (Medina Delgado, 2019, p. 16). Dicho individuo se halló asociado a dos tupus metálicos, se tiene restos de camélido en mayor frecuencia, roedor, entierro de un cánido y hasta de un servido.

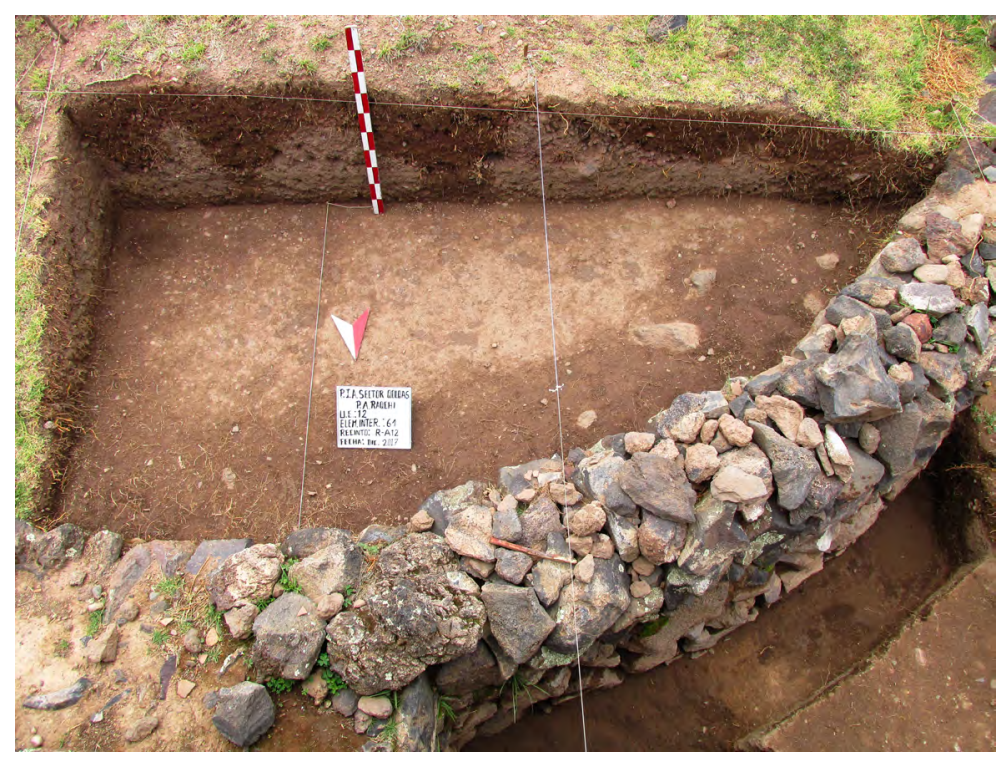

Figura 21. Contexto funerario secundario en el interior y contiguo al muro oeste del recinto A-12.

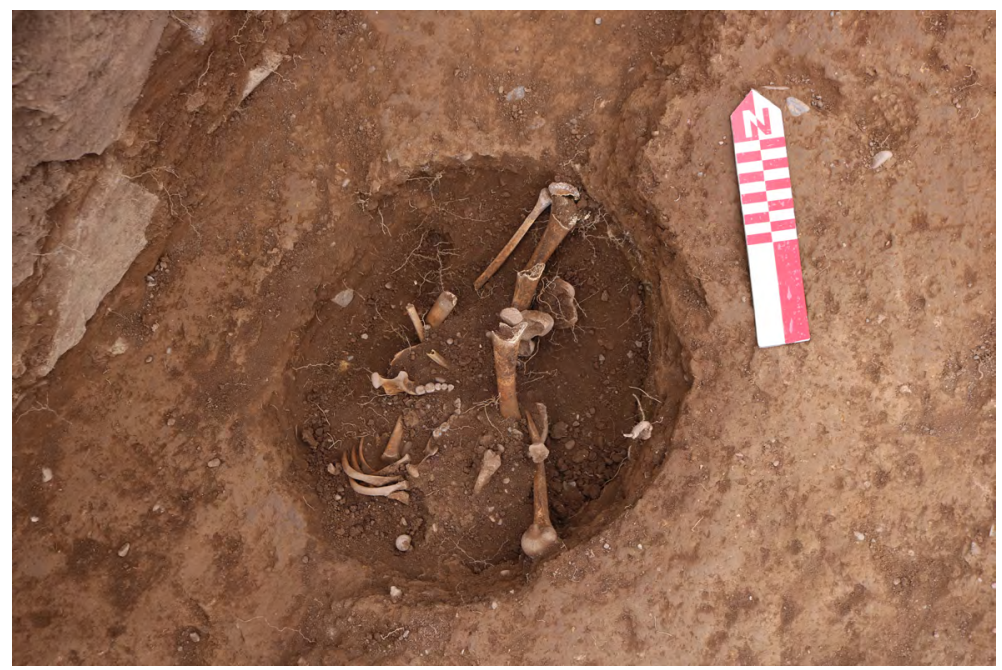

Figura 22. Restos óseos de 03 individuos, 01 individuo adulto mayor y 02 individuos subadultos. 

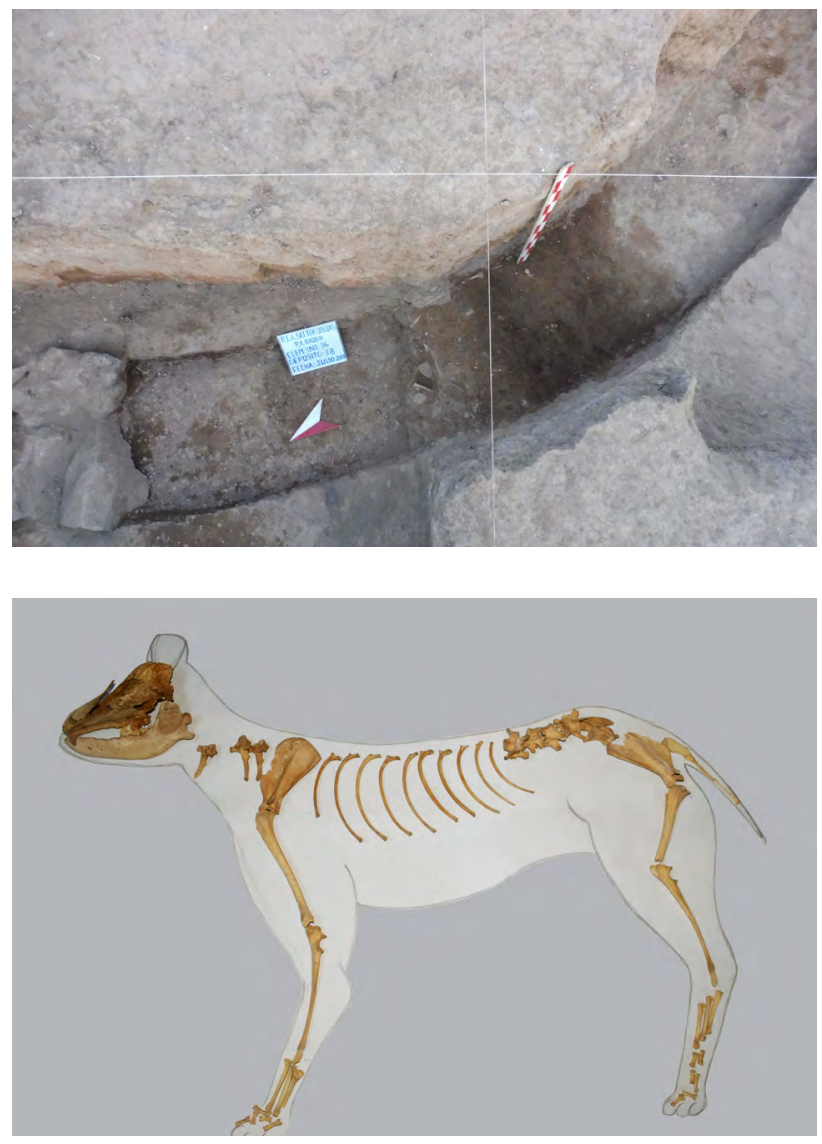

\section{Material lítico}

En el borde, en el filo o incluso en la superficie de los útiles líticos pueden quedar residuos o huellas de uso como resultado de su utilización para tareas diversas. Por huellas de uso entendemos aquellos cambios físicos que se producen en los bordes de un útil lítico como resultado de su uso (Domingo, Burke, \& Smith, 2017, p. 249).

Los materiales líticos hallados incluyen fragmentos de tunawa ( $a, b$ y c), tunawa con huellas de uso en la parte activa (d), percutores líticos (e-k), una boleadora (l) y lascas de obsidiana, cuentas de crisocola de color verde turquesa
Figura 23. Entierro de un cánido en la base de la cimentación del recinto $F-10$ (lado oeste), depósito 35, y nivel -2.30 $\mathrm{m}$ del nivel cero a $0.80 \mathrm{~m}$ por debajo de piso de ocupación Inka.

Figura 24. Reconstrucción hipotética del esqueleto de un cánido adulto.

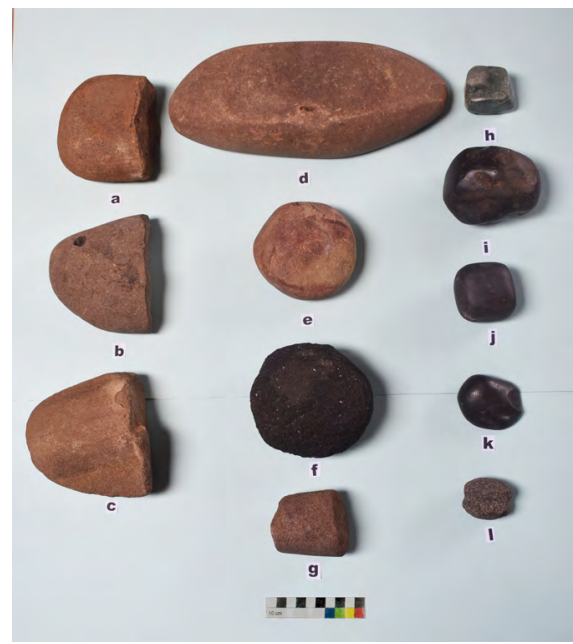

Figura 25. Elementos líticos hallados en el sector Qolqas del Parque Arqueológico de Raqchi. 


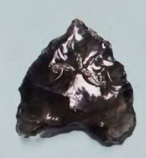

A

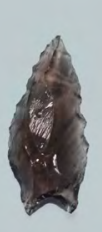

B

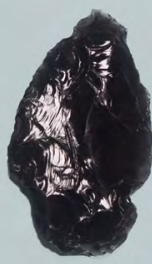

C

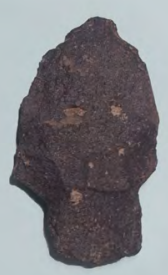

D

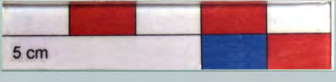

Figura 26. Puntas de obsidiana (a, b, c) una punta lítica (d)

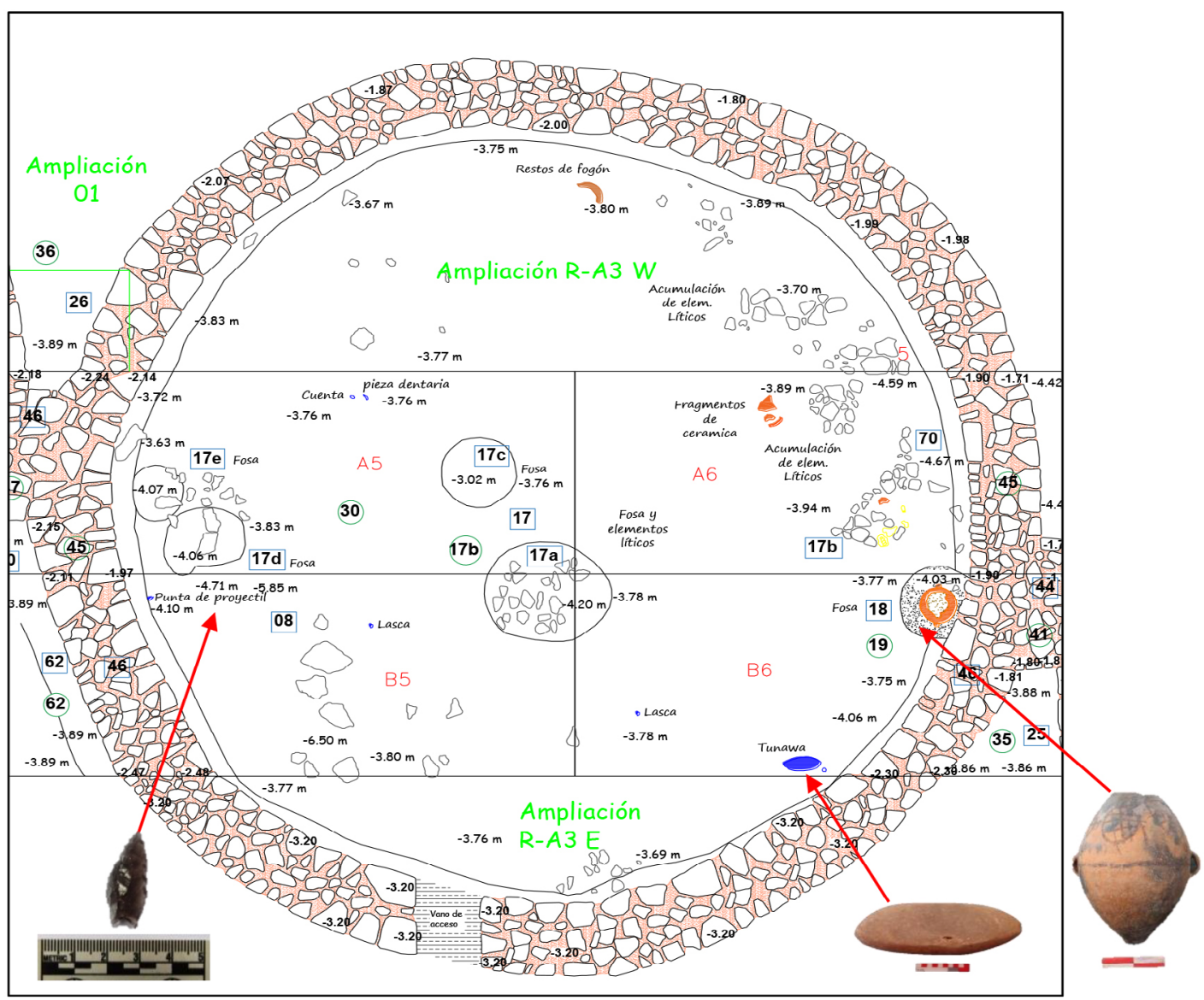

Figura 27. Plano de planta UE 13 (pasadizo longitudinal 01) del sector Qolqa del Parque Arqueológico de Raqchi 


\section{ARQUITECTURA DEL SECTOR QOLQAS}

La arquitectura prehispánica registrada en el sector Qolqas se caracteriza por presentar una distribución espacial conformada por estructuras arquitectónicas de planta circular cuyo diámetro promedio interior varia de $7.30 \mathrm{~m}$ a $7.40 \mathrm{~m}$ y $8.50 \mathrm{~m}$ a 9,50 m de diámetro exterior registrados en las columnas A, B, C, D, E y F (Tabla Nº1). La mayoría de los recintos no se conserva evidencias de techos o del empotramiento de estructuras en los muros, en base a los antecedentes, que estos fueron de forma cónica cubiertos con paja de ichhu.

Los recintos circulares se organizan en columnas horizontales con espacios vinculados por otro común (recinto a recinto) o espacios contiguos asociado a pasadizos longitudinales de sur a norte (Psd. Long. 1, 2, 3, 4 y 5) de un ancho $4.00 \mathrm{~m}$ de promedio, las orientaciones de los vanos de acceso de los recintos mantienen un patrón constante en dirección hacia el pasadizo longitudinal.

La planta circular tuvo mucha difusión en los andes y aun se sigue empleando en varios lugares, principalmente en el territorio boliviano. En varios sitios de los andes centrales Nororientales y en el propio territorio quechua, en el Departamento de Apurímac, se encuentra restos arqueológicos que acusan la forma circular de las casas. Es probable que hayan existido también en el área cusqueña antes de la introducción de la arquitectura oficial. Los Inka hicieron uso de la planta circular en edificios que no estaban destinadas a viviendas. Muchos de los depósitos, qollqa, tuvieron planta circular al igual que una considerable cantidad construcciones funerarias, chullpa (Gasparini \& Margolies, 1977, p. 147).

El sistema de circulación en el sector Qolqas presenta un patrón bien definido de este modo se ha identificado un recorrido rectilíneo la cual constituye el eje de circulación en el sector Qolqas a través de los pasadizos longitudinales y transversales (ver figura 28).

El sistema estructural empleado en la construcción de las estructuras arquitectónicas de los recintos circulares del sector Qolqas como principal material constructivo es piedra de origen volcánico como basalto, tova volcánica, andesita basáltica, dichos líticos están dispuestos en su estado natural que corresponde a "Mampostería ordinaria es la que se hace con piedras o mampuestos irregulares, que no han sido objeto de ningún labor, es decir, tal como se arrancan del campo o rio, aunque los cantos rodados no son lo más apropiados para obtener una buena trabazón" (Ravines , 1989, p. 46), unidas con mortero de arcilla que constituyen muros cuyo espesor oscila entre los $0.80 \mathrm{~m}$ en promedio.

\section{CONSERVACIÓN ARQUITECTÓNICA DEL SECTOR QOLQAS}

De acuerdo a la Carta de Venecia "la finalidad de la conservación y restauración se centra en salvaguardar tanto la obra de arte como el documento histórico, es 
decir, se afirma la doble naturaleza (histórica y artística) del monumento" (López Morales \& Vidargas, 2014, p. 19).

La Carta de Venecia examina separadamente la "conservación" y "restauración". La "conservación" se considera, ante todo como un "mantenimiento sistemático", a través de su utilización moderna que, sin embargo, "no debe alterar la distribución y el aspecto del edificio". "La restauración" es considerada como un "proceso que debe tener un carácter excepcional", cuya "finalidad es la de conservar y poner de relieve los valores formales e históricas del monumento, y se fundamenta en el respeto a los elementos antiguos y a las partes auténticas" (López Morales \& Vidargas , 2014, p. 19-20). (Cuadro 2)

La puesta en valor, como explica José Hayakawa (2012), "es una operación técnica y sistemática cuyo fin es darle un nuevo uso a un bien conforme a su naturaleza, destacando y exaltando sus características y valores" (en Arciga Soto, 2018, p. 16)



Figura 28. Distribución arquitectónica del sector qolqas con una planificación ortogonal y lineal con pasadizos longitudinales y transversales 


\begin{tabular}{|l|l|l|}
\hline \multicolumn{3}{|c|}{ TIPOLOGÍA DE LESIONES Y AGENTES CAUSANTES } \\
\hline \multicolumn{1}{|c|}{ TIPOLOGÍA DE LESIONES } & \multicolumn{1}{|c|}{ SINTOMATOLOGÍA } & \multicolumn{1}{c|}{ AGENTE PATOLÓGICO } \\
\hline Físicas & $\begin{array}{l}\text { Humedad } \\
\text { Metereorización } \\
\text { Erosión física }\end{array}$ & $\begin{array}{l}\text { Condiciones atmosféricas } \\
\text { Presencia de agua }\end{array}$ \\
\hline Mecánicas & $\begin{array}{l}\text { Grietas } \\
\text { Fisuras } \\
\text { Deformaciones } \\
\text { Desprendimiento } \\
\text { Erosión mecánica }\end{array}$ & $\begin{array}{l}\text { Uso continuo } \\
\text { Carga y sobre carga } \\
\text { Dilataciones } \\
\text { Acción eólica }\end{array}$ \\
\hline Químicas & $\begin{array}{l}\text { Disgregación } \\
\text { Deformación } \\
\text { Eflorescencia }\end{array}$ & $\begin{array}{l}\text { Contaminantes ambientales } \\
\text { Presencia de agua } \\
\text { Temperatura }\end{array}$ \\
\hline Biológicas & Degradación de morteros & Presencia de hongos y líquenes \\
\hline Antrópicas & & $\begin{array}{l}\text { Actividad agrícola } \\
\text { Huaqueo } \\
\text { Vandalismo }\end{array}$ \\
\hline
\end{tabular}

Cuadro $N^{\circ}$ 02: Afectaciones patológicas identificados en el sector Qolqas

Según María del Carmen Díaz (2010) entiende así la puesta en valor:

El término empleado en italiano es: valorizzazione. Es un término de una gran amplitud, ya que puede indistintamente asumir una acción inmaterial o una acción directa o material, que implique una acción constructiva. Un mecanismo de puesta en valor puede conllevar medidas de preservación y de tutela activa, para accionar en pos de una buena utilización, respetando su historicidad y asegurando su vida útil. Los procesos de puesta en valor implican el planteo de objetivos definidos y una investigación profunda del bien que conduzca a un diagnóstico certero de los valores y visualización de sus posibles usos. Es importante también que se incluyan medidas adecuadas para gestionar la divulgación para el conocimiento de los valores culturales por parte de la población (en Arciga Soto, 2018, p. 17)

\section{DISCUSIÓN}

Considerando la propuesta de arqueotectura se entiende por Arquitectura la manipulación antrópica de un espacio dado mediante técnicas constructivas que varían a lo largo del tiempo atendiendo a factores sociales, culturales y económicos. La arquitectura estaría relacionada tanto con su entorno físico como con la sociedad que la genera, siendo su forma concreta fruto de una idea o percepción compartida por la colectividad de individuos de una sociedad, y por lo tanto comprensible dentro 
de ella, directamente relacionada con los códigos de uso y concepción del espacio y con los esquemas de pensamiento de esa sociedad (Mañana Borazas \& Blanco Rotea, 2002, p. 14). En ese sentido el sector Qolqas del parque arqueológico de Raqchi, la sociedad Inka se basó en conceptos de pensamiento y manejo de espacio en concordancia con el paisaje natural, estableciendo su ubicación en lugares estratégicos de manera planificada, cabe resaltar que las técnicas constructivas del sector Qolqas varían respecto a otros sitios arquitectónicos Inka (patrón clásico rectangular) en cuanto a su tipología constructiva arquitectónica de estructuras circulares, tecnología y diseño. Por ende, la arquitectura constituye un producto cultural de una organización social como de la sociedad Inka.

El diseño de las poblaciones características del planeamiento urbano oficial fue fuertemente influenciado por una serie de factores originados en las creencias, idiosincrasia y costumbres del pueblo Inca. La forma, ubicación, orientación, organización, tipo de composición, dimensionamiento y relación con el medio ambiente de las poblaciones, resultaban, así, consecuencias de la presencia más o menos vigorosos de esos factores (Agurto Calvo, 1987, p. 63).

La metalurgia en tiempo de los incas recoge la herencia tecnológica de más de 2000 años de trabajo del metal en la vasta región de los Andes Centrales. El cobre y sus aleaciones, la plata y el oro fueron metales ampliamente utilizados (Rovira, 2017, p. 97)

Una característica que se halló en las unidades de excavación del sector Qolqas son los metales como: tupus, pinzas y agujas hallados sobre el piso de ocupación Inka. El cobre $(\mathrm{Cu})$ fue el metal con mayor volumen de producción en la época prehispánica y particularmente los metales del sector Qolqas están constituidos en mayor porcentaje por dicho elemento metálico.

Es ampliamente conocido que las aleaciones de base cobre utilizadas en los Andes Centrales fueron el cobre arsenical o bronce arsenical y el bronce al estaño. Asumimos que durante el breve desarrollo del Imperio inca fue el bronce cobreestaño la aleación predominante, usada en la fabricación de objetos (Rovira, 2017, p. 101).

Manzanilla (1986). En nuestros proyectos, definimos al área de actividad como concentraciones y asociaciones de materias primas, instrumentos, productos semiprocesados y desechos en superficies específicas o en cantidades que reflejen procesos particulares de producción, consumo, almacenamiento o desecho...Al analizar un sector determinado de un sitio arqueológico es necesario, pues, abordar el problema de la función específica a la que están destinadas las construcciones (Manzanilla, 2007, p. 448).

En el sector Qolqas se tiene como evidencias fragmentos de tunawa, percutores liticos, una boleadora, desechos de ceniza y carbón disperso, restos óseos de camélido, osamenta calcinada de animal, carbón vegetal, grano de almidón de maíz (Zea mays), 
Chenopodium quinoa (quinua), Ipomoea batatas "camote", las cuales son características de una actividad de manufactura, uso, consumo, almacenamiento y desechos en un espacio determinado como el sector Qolqas del parque arqueológico de Raqchi.

Por otra parte, el tratamiento de piso de ocupación Inka esta constituido por elementos líticos regulares y pequeños en su estado natural unidos con mortero dispuestas a manera de empedrado, sobre suelo tipo grava arenoso.

Es remarcable la rentabilidad que conlleva la proyección de programas de investigación sobre arquitectura prehistórica e histórica en los que la investigación arqueológica se ha enfocado con una clara orientación patrimonial. Así pues, el plan de trabajo reseñado se implica en proyectos integrales de Gestión del Patrimonio arquitectónico, en los que la investigación básica constituye el punto de partida de un proceso que culmina en la puesta en valor y divulgación del Patrimonio Arqueológico. En estos proyectos, Arqueotectura no se reduce a una mera práctica interpretativa, sino que actúa como una técnica que, por un lado, se adapta y responde a los problemas planteados por la existencia del Patrimonio Arqueológico, y por otro, genera conocimiento que revierte en la propia sociedad (Mañana Borazas \& Blanco, Rotea, 2002, p. 24).

El proyecto de investigación arqueológica del sector Qolqas del Parque Arqueológico de Raqchi, es con fines de conservación y puesta en valor, (recuperación del monumento pre hispánico sector Qolqas) por la valoración de patrimonio como: valor artístico, valor instrumental, valor de antigüedad, valor simbólico y valor de la autenticidad.

\section{CONCLUSIONES}

1. De acuerdo al análisis estratigráfico, morfológico, estadístico y contextual de materiales culturales asociados, estos recintos son unidades habitacionales, que utilizaron como espacios de usos múltiples relacionados con las actividades domésticas (restos de quema y fogón, carbón vegetal), por el uso de utensilios doméstico como ollas, jarras, platos, cantaros, urpus, cuencos, aríbalos, vasos, aguja metálica, tupus y consumo de carne de camélido por la presencia de restos óseos, herramientas de caza (lascas y punta lítica de obsidiana), percutores y kupanas herramientas agrícolas.

2. Los recintos E-05 y F-06 muestran la fase de abandono y la destrucción del tratamiento de piso de ocupación Inka, por evidencia de restos de quemas y vasijas fragmentadas con mayor incidencia en los vanos de acceso, las unidades arquitectónicas sufrieron el colapso de sus estructuras arquitectónicas en el interior y exterior de los recintos.

3. Se sacaron dos muestras de tierra para el análisis de almidones y fitolitos cuyos resultados indican la presencia de poaceas (gramíneas) almidón de maíz y larvas. 
4. Los pasadizos longitudinales aprovecharon el comportamiento del estrato natural (volcánico y lacustre) por la característica de percolar el agua hacia el subsuelo por sectores, teniendo en cuenta que la formación no es uniforme, se evidenciado la presencia de drenajes de evacuación de aguas pluvial en los pasadizos abiertos 3 y 4 caracterizados por líticos sueltos, grava arenosa.

5. Los pasadizos longitudinales, durante la época Inka sirvió como vía de circulación o comunicación social entre las unidades arquitectónicas distribuidos en forma lineal.

6. Las estructuras arquitectónicas de forma circular distribuidos en forma lineal con vanos de acceso orientados hacia los pasadizos longitudinales y transversal se construyeron en el Horizonte tardío (Inka: 1400 d. C.-1536 d. C.). Los recintos B-06, C-09, C-10, E-05, C-06, E-06, F-06 y F-10 son de uso doméstico, inferido a partir de la potencia (estratigrafía $0.20 \mathrm{~m}$ de espesor) y el material cultural asociado, como son fragmentos de cerámica doméstica que pertenecen a ollas, jarras, cántaros, urpus, platos, aríbalos, restos de ceniza y carbón vegetal disperso, restos de fogón, restos óseos de camélidos con o sin calcinar, metales (agujas, pinzas, tupus), artefactos líticos pulidos (percutores, manos de moler, tunawa), los análisis paleobotánicas realizados arrojan granos de maíz y carbones de papa deshidratada, que corresponde a muestra 06 , recinto $\mathrm{C}-10$.

7. El recinto E-05, de acuerdo a los resultados de análisis palinológico se determinó las siguientes especies: quinua (Chenopodium quinoa), payqo (chenopodium ambrosioides), camote (Ipomoea batatas), ajenjo y santa maría (Ambrosia sp.), familia Poacea y Myrtaceae.

8. Los espacios abiertos (pasadizos longitudinales y transversales), sirven como vías de circulación o articulación entre las unidades arquitectónicas entre si. Estos espacios fueron tratados con material grava arenoso de acuerdo al relieve topográfico, y en algunas partes aperturaron fosas irregulares para el sistema de tratamiento de filtración de aguas pluviales hacia el subsuelo.

9. En el piso de ocupación Inka de los recintos A-10, B-06, C-08, C-09, E-05, F-06 y F-09 se evidenció parte del tratamiento con material limo arenoso, grava y finalmente la disposición de líticos con mortero de arcilla en forma horizontal, de 0.30 $\mathrm{m}$ de espesor promedio. Mientras el piso de los recintos abandono y reocupación (1537 d. C-1824 d. C)

Abandono: Destrucción en los recintos C-09, C-10, E-05, E-06, F-06; mediante el tapiado de los vanos de acceso, rotura de cerámica (ollas, jarras, cuencos, urpus), destrucción de tratamiento de pisos de ocupación Inka (empedrado), arcilla cocida, ceniza, carbón y huesos de camélidos calcinados esparcido en el interior y sobre el umbral de los vanos de acceso de los recintos propio de la actividad que realizaban en ese momento. 
Reocupación: Colapso de las estructuras arquitectónicas, posterior al abandono de los recintos. Los recintos C-09, C-10 y E-05, fueron reocupado asociado a áreas de combustión (ceniza y carbón disperso), fragmentos de cerámica Inka y la división de estructural al interior de los recintos circulares.

En general los recintos circulares fueron afectados por agentes naturales y antrópicos:

Factores naturales, factores climatológicos que influyen negativamente la preservación y conservación de las estructuras arquitectónicas, las raíces de árbol de capulí, y la vegetación de la zona que se han inquistado en los muros dañando y desestabilizando a las estructuras arquitectónicas, las lluvias filtraron en las juntas de los muros arquitectónicos dañando directamente la mampostería provocando pandeamientos, fisuras y perdida de mortero, consecuentemente la perdida de elementos líticos conformantes de las estructuras arquitecturas, de esta manera perdiendo la originalidad circular primigenia de los recintos. Factores antrópicos: la actividad agrícola contemporánea practicada al interior y exterior de los espacios abiertos del sector Qolqas, el pastoreo de animales por parte de los moradores de la comunidad.

AGRADECIMIENTOS: Los resultados presentados en este articulo se derivan de la primera temporada (año 1) del Proyecto de Investigación Arqueológica con fines de conservación y puesta en valor "Recuperación del Monumento Prehispánico Sector Qolqas, del Parque Arqueológico de Raqchi, Distrito de San Pedro, Provincia de Canchis, Departamento Cusco. Agradecemos a la Dirección Desconcentrada de Cultura Cusco por permitirnos dirigir dicho proyecto de investigación y por los permisos y la supervisión de nuestro trabajo. Así mismo agracemos a los arqueólogos participantes en la excavación, registro, interpretación, discusión y redacción del presente artículo son: Werner Delgado Villanueva, Amalia Cáceres Anaya, Daniel Mendoza Hanampa, Ruben Aparicio Laucata, Nicolás Alvino Naveda, Abdul Pumayali Pumayali, Yoel Pañihuara Jaimes, Rita Camino Mamani, Junior Alvarez Melgarejo, Jose A. Huaman Cusihuaman, Fernando Cevantes Lobon otros arqueólogos(as). Hist. Teófilo Cucho Jimenez, Blga. Marisol Saji Saire, a los responsables del laboratorio y gabinete de la Dirección Desconcentrada de Cultura Cusco, Antrop. Oliver Medina Delgado quien analizo los óseos humanos, Blgo. Jacqueline Puelles Yañez rastreo de material orgánica y determinación de osamenta animal, Ing. Químico: Jorge Luis Gamarra Gamio.

\section{REFERENCIAS BIBLIOGRÁFICAS}

Agurto Calvo , S. (1987). Construcción Arquitectura y Planeamiento Incas. Lima: Cámara Peruana de la Construcción .

Arciga Soto, R. (2018). Gestión del Patrimonio Cultural de las casas hacienda de Lima Norte. Lima: Rolando Arciga Soto. 
Domingo, I., Burke, H., \& Smith, C. (2017). Manual de campo del Arqueólogo. Barcelona-España: Ariel, S.A.

Gamarra Gamio, J. L. (2018). Departamento Físico Químico: Resultados de análisis químico por fluorescencia de rayos X. Cusco: Laboratorio Fisicoquímico DDC-Cusco.

Gasparini, G., \& Margolies, L. (1977). Arquitectura Inka. Caracas: Centro de Investigaciones Históricas y Estéticas, Facultad de Arquitectura y Urbanismo- Universidad Central de Venezuela.

Hyslop, J. (2016). Asentamientos Planificados Inka. Lima: Ediciones Cope.

Lopez Morales , F. J., \& Vidargas , F. (2014). Los nuevos paradigmas de la conservación del patrimonio cultural. 50 años de la Carta de Venecia. México: Instituto Nacional de Antropología e Historia .

Manzanilla , L. R. (2007). La unidad domestica y las unidades de producción. Propuesta interdisciplinaria de estudio. México: El Colegio Nacional.

Mañana Borazas, P., \& Blanco Rotea , R. (2002). Arqueotectura 1: Bases Teórico-Metodológicas para una Arqueología de la Arquitectura. Traballos de Arqueoloxia e Patrimonio, 21.

Medina Delgado, O. (2019). Informe Bioarqueólogico: Análisis de osamentas Humanas en gabinete de Antropología Física, DDC-C. Cusco: DDC-C.

Ministerio de Cultura. (2016). Metales de Pachacamac. Lima: Impresores S.A.C.

Ravines , R. (1989). Arqueología Práctica . Lima: Los Pinos E.I.R.L.

Rovira, S. (2017). La Metalurgia Inca: Estudio a partir de las colecciones del Museo de America de Madrid. Instituto Francés de Estudios Andinos , 97.

Vetter Parodi, L., \& Filomena Guerra, M. (2017). La orfebrería en los Andes en la epoca Inca (Siglos XV-XVI). Instituto Francés de Estudios Andinos , 174.

\section{SOBRE LA AUTORA}

\section{Marisa Guadalupe Quispe Cuno}

Licenciada en Arqueólogía por la Universidad Nacional de San Antonio Abad del Cusco, Escuela Profesional de Arqueología. Participación como: jefa de zonas y sitios arqueológicas de la provincia de Calca, Residente en la ejecución del proyecto sector Qonchapata del Parque Arqueológico de Saqsaywaman, Directora del proyecto de 
investigación arqueológica con fines de conservación y puesta en valor del Monumento prehispánico del Parque Arqueológico de Saqsaywaman, sector Inkilltambo, Directora del proyecto de Puesta en valor del templo de San Sebastian-Cusco, Directora del Proyecto de Investigación Arqueológica del Sector Puqro de Parque arqueológico de Saqsaywaman y Director del P.I.A con fines de conservación y puesta en valor "Recuperación del Monumento prehispánico sector Qolqas del Parque Arqueológico de Raqchi, Distrito de San Pedro, Canchis-Cusco". 